\title{
FABRICATION OF FIXTURE FOR CONCENTRIC FOAM FILLING OF TUBES
}

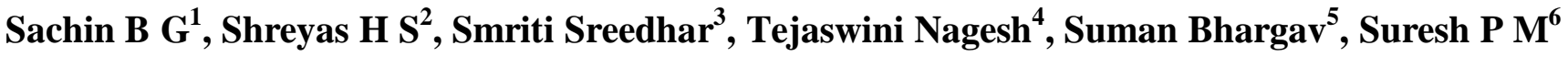 \\ ${ }^{1}$ U.G. Student, Department of Mechanical Engineering, K. S. Institute of Technology, Bangalore, Karnataka, India \\ ${ }^{2}$ U.G. Student, Department of Mechanical Engineering, K. S. Institute of Technology, Bangalore, Karnataka, India \\ ${ }^{3}$ U.G. Student, Department of Mechanical Engineering, K. S. Institute of Technology, Bangalore, Karnataka, India \\ ${ }^{4}$ U.G. Student, Department of Mechanical Engineering, K. S. Institute of Technology, Bangalore, Karnataka, India \\ ${ }^{5}$ Research Scholar, VTU Regional Resource Centre, Belagavi, Karnataka, India \\ ${ }^{6}$ Prof. \& Head, Department of Mechanical Engineering, K.S. Institute of Technology, Bangalore, Karnataka, India. ${ }^{3}$
}

\begin{abstract}
A fixture is a work-holding or support device used in the manufacturing industry. Fixtures are used to securely locate (position in a specific location or orientation) and support the work, ensuring that all parts produced using the fixture will maintain conformity and interchangeability. A fixture's primary purpose is to create a secure mounting point for a workpiece, allowing for support during operation and increased accuracy, precision, reliability, and interchangeability in the finished parts. A fixture was designed in order to hold the tubes in position and facilitate foam filling in between the tubes. The proposed fixture ensured that concentricity was maintained between the tubes and also designed in such a way that it could be configured for different orientations.
\end{abstract}

Keywords: fixture, foam filling, concentricity, orientations, tubes. $* * *$

\section{INTRODUCTION}

A fixture is a work-holding or support device used in the manufacturing industry.A fixture differs from a jig in that when a fixture is used, the tool must move relative to the workpiece; a jig moves the piece while the tool remains stationary.The energy absorption capacity of vehicles and protective structures has become more important due to ever stringent safety requirement. An increasing focus has been paid to the use of energy absorbing devices in order to overcome the adverse effect of an impact load. Many devices have been designed to study impact energy absorption during a collision and hence protect the vehicle components and passengers. Various types of energy absorbers have been placed in vehicle structures, particularly cars as a significant number of road causalities have been caused by car crashes[2]. Materials, such as foams, are used as impact energy absorbers in crash and blast protection because of their unique mechanical behavior. With this promising new material, the present project aims to develop energy-absorbing devices incorporating both thin-walled tubes and foams.In order to fill the foam between two tubes and to ensure concentricity is maintained, a fixture is designed and fabricated.[3]

\section{BASIC DESIGN}

The fixture was designed in such a way that it can be used for two concentric configurations of the tubes, i.e. , the outer tube of dimension $50 \mathrm{~mm} \mathrm{X} 50 \mathrm{~mm}$ with an inner tube of dimensions, either $25 \mathrm{~mm}$ X $25 \mathrm{~mm}$ or $25 \mathrm{~mm} \mathrm{X} 37.5 \mathrm{~mm}$. These configurations can be obtained by using a locator corresponding to the dimensions of the inner tubes. Also designed such that two orientations of the concentric configuration is possible, i.e. at $0^{\circ}$ and $45^{\circ}$. These orientations can be changed by rotating the orientation plate. The material used for the main components of the fixtures is mild steel[3], A detailed list of the components used in the fixture is given below:

- Base plate: It forms the base of the fixture. It is a square plate of $200 \mathrm{~mm}$ side dimension and $15 \mathrm{~mm}$ in thickness, consisting of 8 holes of $10 \mathrm{~mm}$ diameter which is drilled at $140 \mathrm{~mm}$ pitch circle diameter ( PCD ). Using milling process, a circle of $100 \mathrm{~mm}$ diameter is machined upto a depth of 5mm. Fig 1 shows Base plate used in the fixture.

- Orientation plate: It is a circular plate of $180 \mathrm{~mm}$ diameter and a thickness of $15 \mathrm{~mm}$. It also consists of 8 holes of $10 \mathrm{~mm}$ diameter at $140 \mathrm{PCD}$. It also consists of a square hole of $50.8 \mathrm{~mm}$ side. The alignment of 4 holes with respect to the stud decides the orientation the tubes. Fig 2 shows the orientation plate used in the fixture.

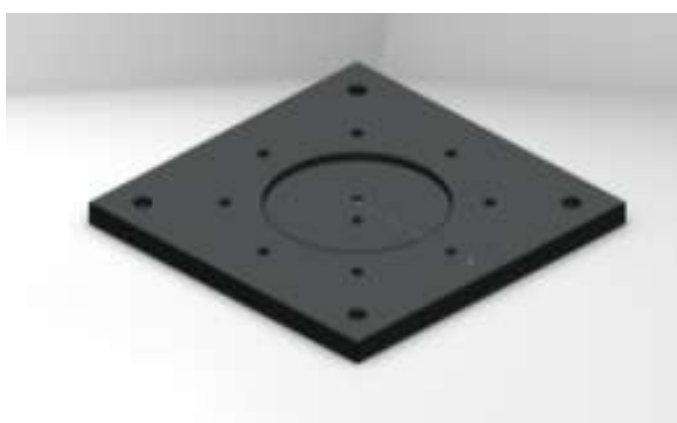

Fig 1: Base plate 


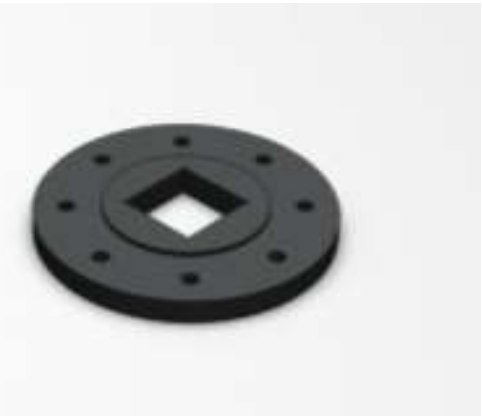

Fig 2 Orientation plate

- Locator :It decides the concentricity of the tubes. Two locators of $1.5 "$ and $1 "$ are used in this fixture. It is mounted at the centre of the base plate with the help of dowel pins. Two holes of $5 \mathrm{~mm}$ diameter are drilled for both the locators diagonally such that any one of the locator can be used as per the required configuration, i.e., $25 \mathrm{mmX} 25 \mathrm{~mm}$ and $25 \mathrm{mmX} 37.5 \mathrm{~mm}$ with respect to the $50 \mathrm{mmX} 50 \mathrm{~mm}$ square tube. Fig 3 and Fig 4 shows the locators used in the fixture.

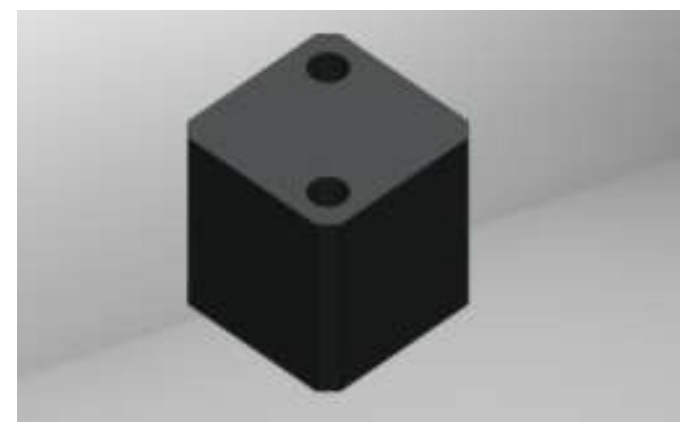

Fig 3 Locator for $25 \mathrm{mmX} 25 \mathrm{~mm}$ tube

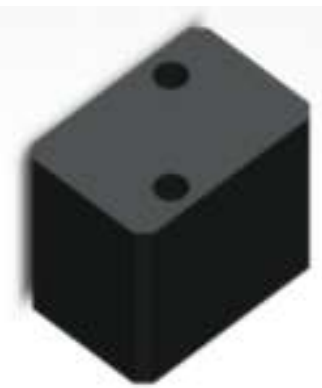

Fig 4 Locator for $25 \mathrm{mmX} 37.5 \mathrm{~mm}$ tube

- Dowel Pins: They are used to mount the locator on the base plate .Dowel pins of $5 \mathrm{~mm}$ diameter and $20 \mathrm{~mm}$ in length are used to hold the locator at the centre of the base plate. Fig 5 shows the dowel pin used in the fixture. Two such pins are used.

- Supporting leg: It consists of 4 legs in order to give a rigid support to the fixture. The legs are of $50 \mathrm{~mm}$ height and $20 \mathrm{~mm}$ in diameter is fixed to the bottom of the base plate using IS 2269 - M6 x 25-Nscrews. Fig 6 shows the supporting leg used in the fixture. Four such legs are used.

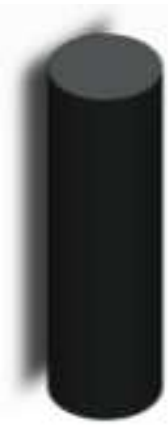

Fig 5 Dowel pin

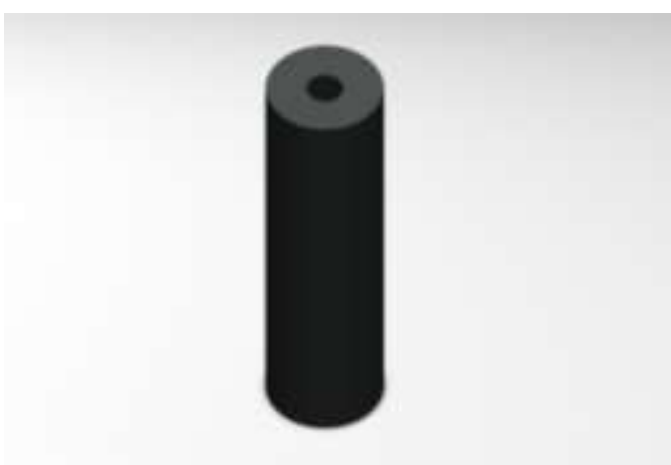

Fig 6 Supporting leg

- Cover Plate: It is used asthe top plate of the fixture to prevent the leaking of the chemicals during chemical reaction while filling the foam. It is a circular plate of $180 \mathrm{~mm}$ diameter of $15 \mathrm{~mm}$ thickness, consisting of 8 holes of $10 \mathrm{~mm}$ diameter at 140 PCD. Fig 7 shows the cover plate used in the fixture.

- Stud : It is a metal rod or shaft with threads on both ends. There are four studs used in this fixture which holds the cover plate and the bottom plate together through the orientation plate. A stud of diameter $10 \mathrm{~mm}$ is used, which is fixed by IS 1364-3 - M10-W-N at the top, and the IS 2269 - M6 x 25-N screws at the bottom. Fig 8 shows the stud used in the fixture.

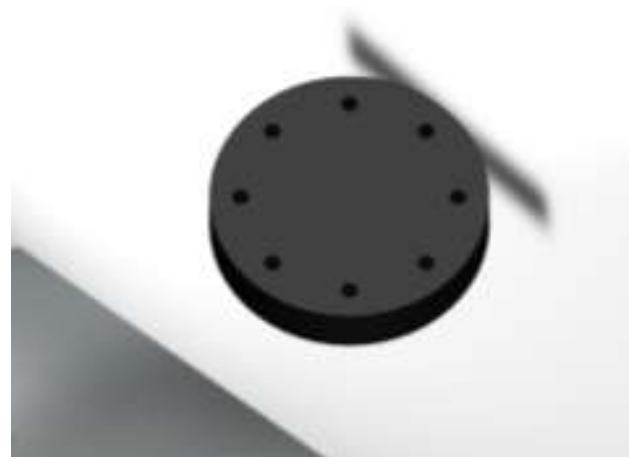

Fig 7 Cover plate 


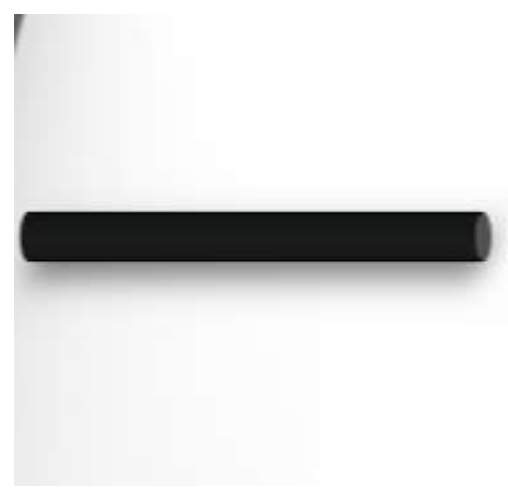

Fig 8 Stud

\section{FOAM FILLING}

Two tubes are placed in the fixture with the help of locators which ensures concentricity of the tubes. Here 1.5" locator is used since the tubes chosen are $2 \mathrm{X} 2$ inch and $1 \mathrm{X} 1.5$ inch. Polyol and methyl di isocyanate[4] are taken in the ratio $1: 1.3(35 \mathrm{ml})$ so as to get the required density, which is $80 \mathrm{~kg} / \mathrm{m}^{3}$. The mixture of these chemicals is filled in the space in between the tubes. Cover plate, stud and nuts are used to cover the tubes in order to prevent overflowing of chemicals during chemical reaction. Cover plate ensures uniform pressure during the chemical reaction between these chemicals.[5] Thus, filling the entire space in between the tubes. The concentric Aluminium tubes with foam filled in between is as shown in Fig 9 and the final assembly of the fixture is as shown in Fig 10.

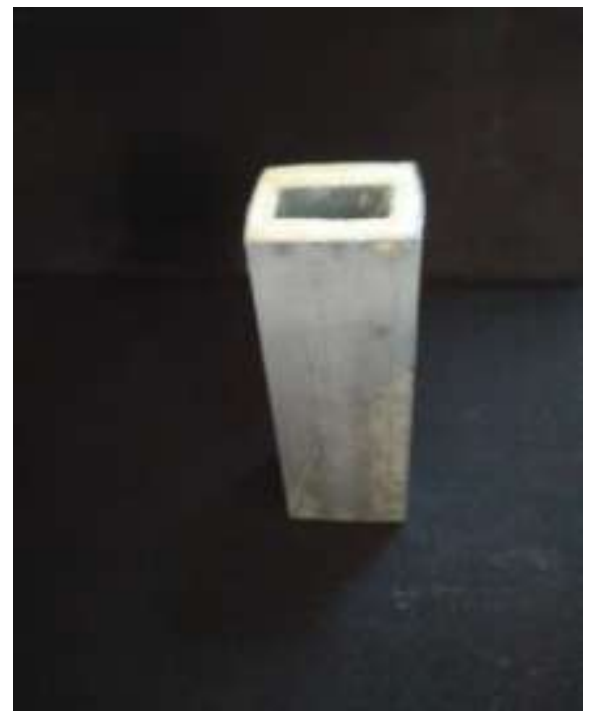

Fig 9: Foam filled concentric $\mathrm{Al}$ tubes

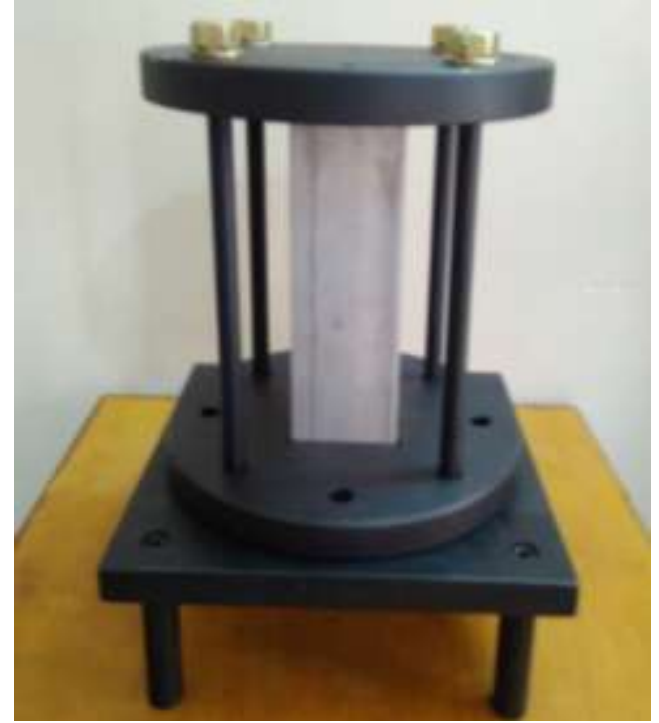

Fig 10: Final fixture assembly

\section{CONCLUSION}

The process of foam filling in the tubes used to be tedious and did not yield optimum results. With the use of this fixture, it was found that the foam filling was uniform in between the tubes and avoided any kind of leakage of chemicals while filling. The firmly fixed cover plate ensures constant pressure during the formation of foam. While this fixture can be used for two configurations and two orientations, alterations can be made in the design which would make it compatible for different configurations and different orientations.

\section{REFERENCES}

[1] P. D. Campbell, Basic fixture design. Industrial Press Inc., 1994.

[2] FAN ZHIHUA, "ENERGY ABSORPTION OF THIN-WALLED EMPTY AND FOAM-FILLED TUBES," Sch. Mech. Aerosp. Eng. Nanyang Technol. Univ. Singap., pp. 31-37, Jan. 2013.

[3] J. A. Lavoie and J. Morton, "Design and application of a quasistatic crush test fixture for investigating scale effects in energy absorbing composite plates. MS Thesis," 1993.

[4] D. H. R. V. Sunil Kumar PR1, "Evaluation for Energy Absorbing Capacity of Concentric Aluminium Tubes Filled With Foam of Different Density," Int. J. Mech. Ind. Technol., vol. 2, no. 1, pp. 113-124, Apr. 2014.

[5] G. Olabi, E. Morris, M. S. J. Hashmi, and M. D. Gilchrist, "Optimised design of nested circular tube energy absorbers under lateral impact loading," Int. J. Mech. Sci., vol. 50, no. 1, pp. 104-116, 2008. 